\title{
Spatial and temporal variations of vegetation cover and the relationships with climate factors in Inner Mongolia based on GIMMS NDVI3g data
}

\author{
TONG Siqin $^{1,2}$, ZHANG Jiquan $^{1 *}$, BAO Yuhai ${ }^{2}$, Wurina $^{1}$, Terigele $^{2}$, Weilisi ${ }^{3}$, Lianxiao $^{4}$ \\ ${ }^{1}$ School of Environment/Natural Disaster Research Institute, Northeast Normal University, Changchun 130117, China; \\ ${ }^{2}$ College of Geographic Science, Inner Mongolia Normal University, Hohhot 010010, China; \\ ${ }^{3}$ Graduate School of Engineering, Gifu University, Gifu 501-1193, Japan; \\ ${ }^{4}$ Graduate School of Life and Environmental Sciences, Tsukuba University, Ibaraki 305, Japan
}

\begin{abstract}
Variation in vegetation cover in Inner Mongolia has been previously studied by the remote sensing data spanning only one decade. However, spatial and temporal variations in vegetation cover based on the newly released GIMMS NDVI3g data spanning nearly thirty years have yet to be analyzed. In this study, we applied the methods of the maximum value composite (MVC) and Pearson's correlation coefficient to analyze the variations of vegetation cover in Inner Mongolia based on GIMMS NDVI3g data spanning from 1982 to 2013. Our results indicate that the normalized difference vegetation index (NDVI) increased at a rate of $0.0003 /$ a during the growing seasons despite of the drier and hotter climate in Inner Mongolia during the past three decades. We also found that vegetation cover in the southern agro-pastoral zone significantly increased, while it significantly decreased in the central Alxa. The variations in vegetation cover were not significant in the eastern and central regions. NDVI is positively correlated with precipitation $(r=0.617, P=0.000)$ and also with air temperature $(r=0.425, P=0.015)$, but the precipitation had a greater effect than the air temperature on the vegetation variations in Inner Mongolia.
\end{abstract}

Keywords: GIMMS NDVI3g; vegetation cover; spatiotemporal variation; climate change

Citation: TONG Siqin, ZHANG Jiquan, BAO Yuhai, Wurina, Terigele, Weilisi, Lianxiao. 2017. Spatial and temporal variation of vegetation cover and its relationship with climate factors in Inner Mongolia based on GIMMS NDVI3g data. Journal of Arid Land, 9(3): 394-407. doi: 10.1007/s40333-017-0016-4

\section{Introduction}

Vegetation is an important component of terrestrial ecosystem and a key link in the processes of land surface energy exchange, water cycle, and biogeochemical cycle. It also plays an important role in the interception of rainfall, reduction of runoff, prevention of desertification, and soil and water conservation in arid and semi-arid ecological systems (Chen et al., 2007). The normalized difference vegetation index (NDVI) is an indicator of vegetation growth and spatial distribution density (Franklin et al., 2011). The principle of NDVI is that as chlorophyll absorbs red light during photosynthesis, vegetation with higher growth rates will absorb more red light and reflect more near-infrared light than slower growing vegetation (Xue et al., 2011). Thus, NDVI can reflect the intensity of photosynthesis and has been widely used for phenology and vegetation studies (Tucker et al., 1986; Sellers et al., 1995; Clerici et al., 2012; Liu et al., 2015; Tang et al., 2015).

NDVI data were derived from Moderate Resolution Imaging Spectrometer (MODIS), 
Advanced Very High Resolution Radiometer (AVHRR), and SPOT-VEGETATION imagery. The third generation of AVHRR NDVI data (NDVI3g), produced by the Global Inventory Modelling and Mapping Studies (GIMMS) group, covers the period from July 1981 to December 2013. AVHRR NDVI data have been widely used to study the global and regional vegetation variations and the responses to climatic changes. For example, Tucker et al. (1985) used AVHRR data to monitor vegetation cover changes on the African continent; Wang et al. (2015) used GIMMS NDVI to analyze spatial and temporal variations in vegetation cover and the responses to climatic change in Ghana; and Jiang et al. (2013) found that the responses of vegetation to climate change as measured by NDVI3g are more acceptable than those measured by the previous version of GIMMS (NDVI1g) in middle to high latitudes of the northern hemisphere.

Natural grassland is the largest terrestrial ecosystem in China, occupying $40 \%$ of the total land area of the country. Grassland in Inner Mongolia is a typical mid-latitude semi-arid temperate steppe ecosystem, accounting for $22 \%$ of the national grassland area (Xin et al., 2015). According to the International Geosphere-Biosphere Programme (IGBP), Inner Mongolia is one of the areas that have been rather sensitive to global climate change (Dong et al., 2000). In addition, vegetation variations in Inner Mongolia have been affected by human activities (Liu and Gao, 2009). Vegetation changes and the influential factors in Inner Mongolia based on remote sensing data have been previously researched (Chen and Zheng, 2008; Chen and Wang, 2009; Mu et al., 2012; Tian et al., 2015). However, none of these researches were based on thirty years of data, i.e., NDVI3g data. The objectives of this study were: (1) to analyze the changes in NDVI, precipitation, and temperature during growing seasons of different administrative divisions in Inner Mongolia over the past 30 years; and (2) to explore the influential factors dictating the variations in NDVI. It is hoped that this study can provide scientific references to verify the effectiveness of ecological protection and vegetation restoration projects in the region.

\section{Materials and methods}

\subsection{Study area}

The Inner Mongolia Autonomous Region is located in the northern part of China, and lies between $37^{\circ} 24^{\prime}-53^{\circ} 23^{\prime} \mathrm{N}$ and $97^{\circ} 12^{\prime}-126^{\circ} 04^{\prime} \mathrm{E}$ (Fig. 1a). It has a total area of about $1.18 \times 10^{6} \mathrm{~km}^{2}$ $(12.3 \%$ of the total area of China), making it the third largest administrative unit in the country. Due to the influence of the East Asian monsoon, it has a temperate continental climate, except for the northern section of the Great Hinggan Range that has a cold continental climate (Niu, 2000). The annual mean air temperature increases southwestward (Fig. 1b). However, annual precipitation decreases southwestward (Fig. 1c). Due to the southwestward decreasing gradient of precipitation and the southwestward increasing gradient of temperature, the vegetation types are spatially well differentiated in Inner Mongolia from the northeast to southwest and consequently the annual mean NDVI value decreases from the northeast to the southwest as well (Fig. 1d). According to climatic characteristics, we divided the study area into three geographic regions in order to analyze the changes in vegetation and climate. The eastern region includes Hulun Buir City, Hinggan League, Tongliao City, and Chifeng City; the central region includes Xilin Gol League, Ulanqab City, Hohhot City, and Baotou City; and the western region includes Ordos City, Bayannur City, Wuhai City, and Alxa League (Bao et al., 2010; Na, 2015).

\subsection{Data sources and pre-processing}

\subsubsection{NDVI data}

GIMMS NDVI3g data were downloaded from the NASA Ames Ecological Forecasting Lab (http://ecocast.arc.nasa.gov). The data have a spatial resolution of $0.083^{\circ}$ with a $15 \mathrm{~d}$ temporal resolution. This dataset was validated with radiometric calibration, atmospheric attenuation, cloud screening, orbital drift, sensor degradation, view and illumination geometry, and other effects that are not associated with vegetation change (Tucker et al., 2005). Monthly NDVI was generated with the maximum value composite (MVC) method. MVC selects the highest value 

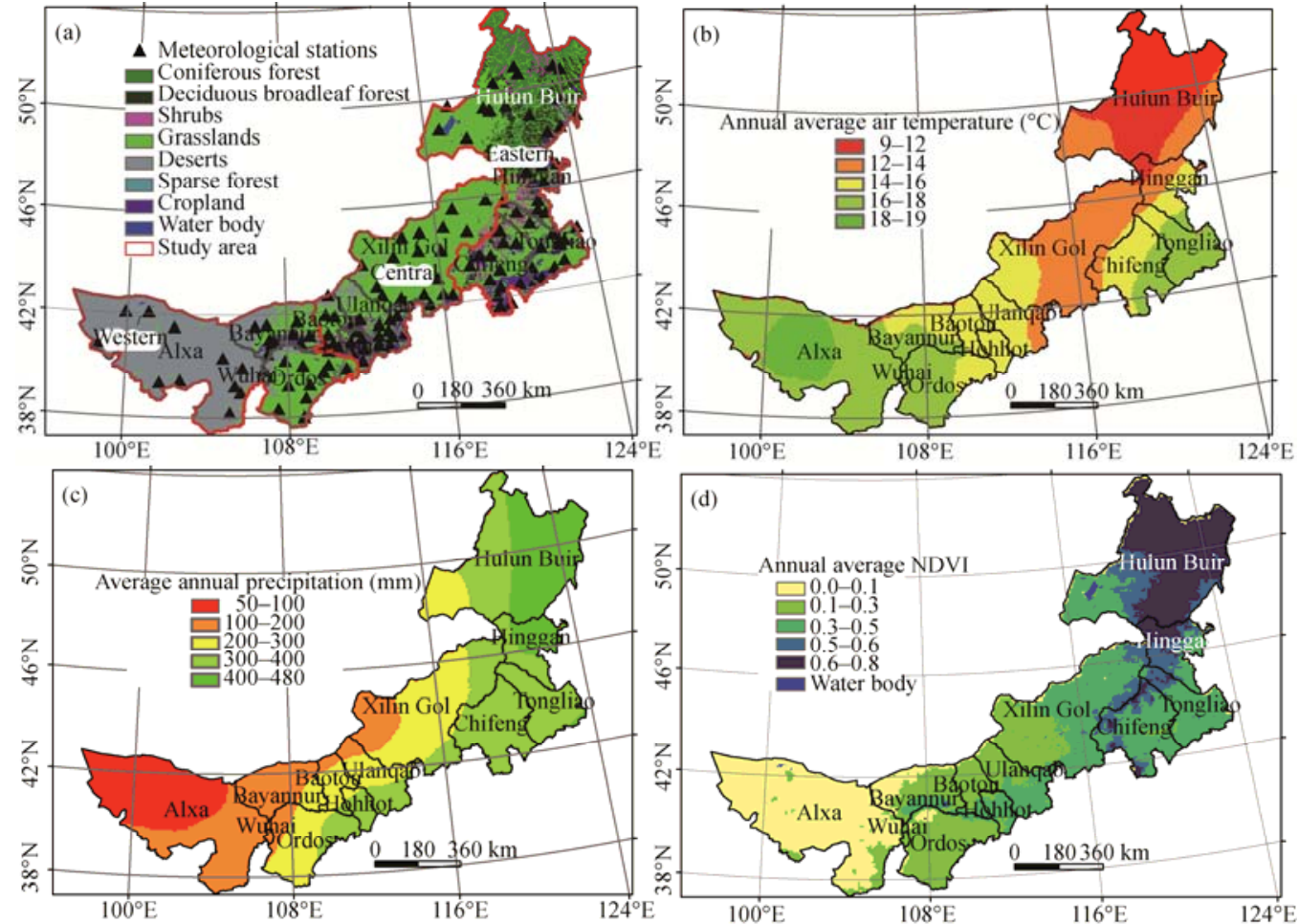

Fig. 1 (a) Location of study area and distribution of vegetation types, (b) annual average air temperature, (c) average annual precipitation, and (d) annual average NDVI during growing-season from 1982 to 2013.

of each pixel from multi-temporal data to represent the current NDVI value (Holben, 1986). The annual growing-season NDVI was defined as the average of NDVI values from April to October in each calendar year (Piao et al., 2006; Guo et al., 2007).

\subsubsection{Climate data}

The climate data used in this study were acquired from the China Meteorological Data Sharing Service System (http://data.cma.cn/), including monthly mean air temperature and monthly precipitation for the period of 1982-2013, measured from 118 meteorological stations that cover the entire area of Inner Mongolia. Considering the longitude, latitude, and elevation of the meteorological stations, we used ArcGIS 10.2 and employed ordinary Kriging method for interpolating the spatial distributions of precipitation and temperature. The obtained raster data had a spatial resolution that was consistent with the NDVI. Growing season precipitation and temperature were calculated as the total monthly precipitation and total monthly temperature, respectively, from April to October.

\subsubsection{Vegetation map}

Information on the distribution of different vegetation types (Fig. 1a) was obtained from the vegetation map of Inner Mongolia with a scale of 1:1,000,000 which was provided by the Data Sharing Infrastructure of Earth System Science (http://www.geodata.cn). A vegetation map was generated with a spatial resolution of $0.083^{\circ}$, which corresponds to GIMMS NDVI. All the spatial datasets are unified to the following coordinate system parameters: central meridian: $105^{\circ}$; standard parallel $1: 25^{\circ}$; standard parallel $2: 47^{\circ}$; latitude of origin: 0 . Albers equal area conic projection was used with the WGS_1984 datum.

\subsection{Methods}

\subsubsection{Linear regression}

Linear regression was used to analyze the temporal trends of vegetation variations for each pixel and regression is expressed by Equation 1: 


$$
y=a+b x .
$$

Where $y$ is the annual NDVI value from 1982 to 2013; $x$, the year from 1982 to 2013; and $a$ and $b$ are the intercept and slope of annual NDVI, respectively, the latter (i.e., NDVI) being calculated by the least squares method (Eq. 2):

$$
\text { Slope }=\frac{n \times \sum_{i=1}^{n} i \times N D V I_{i}-\sum_{i=1}^{n} i \sum_{i=1}^{n} N D V I_{i}}{n \times \sum_{i=1}^{n} i^{2}-\left(\sum_{i=1}^{n} i\right)^{2}} .
$$

Where $n$ is the number of years (equal to 32 in this study), denoting the year $(=1,2,3, \ldots, 32)$; and $N D V I_{i}$ represents the annual mean NDVI value in the $i^{\text {th }}$ year. When the slope $>i$, NDVI is increasing, and when the slope is $<i$, it is decreasing (Liu et al., 2012). The spatial and temporal variations of the climate factors are also derived using similar algorithm.

2.3.2 NDVI-climate correlation analysis

To assess the effects of climate variables on vegetation dynamics, we calculated the Pearson's correlation coefficients (Eq. 3) for growing-season NDVI, temperature, and precipitation for each pixel. If the correlation coefficient is larger than 0 , the two variables are positively correlated, and vice versa.

$$
r_{x y}=\frac{\sum_{i=1}^{n}\left[\left(x_{i}-\bar{x}\right)\left(y_{i}-\bar{y}\right)\right]}{\sqrt{\sum_{i=1}^{n}\left(x_{i}-\bar{x}\right)^{2} \sum_{i=1}^{n}\left(y_{i}-\bar{y}\right)^{2}}} .
$$

Where $r_{x y}$ is the correlation coefficient between two variables $x$ and $y$, with a value ranging from -1 to 1 (a larger absolute value indicates stronger correlation); $i$, the year from 1 to 32 in the study period; $n$, the total period of time (i.e., 32 years in this study). $x_{i}$, the growing-season NDVI in the $i^{\text {th }}$ year; $y_{i}$, the growing-season temperature or precipitation in the $i^{\text {th }}$ year; and $\bar{x}$ and $\bar{y}$ are the mean NDVI, and mean temperature or mean precipitation, respectively, in the growing-season from 1982 to 2013.

\subsubsection{Mann-Kendall statistical test}

The Mann-Kendall statistical test (MK) is a non-distribution (also known as non-parametric statistical) test (Douglas et al., 2000; Zhang et al., 2000; Partal and Kahya, 2006), in which the dataset does not need to be in a particular order and is not affected by outliers. The MK test of a time series is computed by Equations 4-6:

$$
\begin{gathered}
S=\sum_{i=1}^{n-1} \sum_{j=i+1}^{n} \operatorname{sgn}\left(X_{j}-X_{k}\right), \\
\operatorname{sgn}\left(X_{j}-X_{i}\right)=\left\{\begin{array}{ccc}
+1 & \text { if } & \left(X_{j}-X_{i}\right)>0 \\
0 & \text { if } & \left(X_{j}-X_{i}\right)=0 \\
-1 & \text { if } & \left(X_{j}-X_{i}\right)<0
\end{array}\right\}, \\
\operatorname{Var}(S)=\frac{1}{18}\left[n(n-1)(2 n+5)-\sum_{p=1}^{q} t(t-1)(2 t+5)\right] .
\end{gathered}
$$

Where $x_{i}$ and $x_{j}$ are the time series data values at time $i$ and $j$, respectively; $n$, the length of the time series; and $t$, the number of ties for the value. In cases where the sample size $n>10$, the standard normal variable $Z_{M K}$ is computed using the Equation 7: 


$$
Z_{M K}=\left\{\begin{array}{ccc}
\frac{S-1}{\sqrt{\operatorname{Var}(S)}} & \text { if } & S>0 \\
0 & \text { if } & S=0 \\
\frac{S+1}{\sqrt{\operatorname{Var}(S)}} & \text { if } & S<0
\end{array}\right\} .
$$

Positive values of $Z_{M K}$ indicate increasing trends, while negative values of $Z_{M K}$ show decreasing trends. When testing either increasing or decreasing monotonic trends, the null hypothesis was rejected for an absolute value of $Z_{M K}$ greater than $Z_{1-(a / 2)}$ obtained from standard normal cumulative distribution tables, where $a$ is the desired significance level. In this study, a significance level of 0.05 was applied.

\section{Results}

\subsection{Spatial-temporal variations in vegetation cover in Inner Mongolia}

\subsubsection{Temporal variations of vegetation cover in Inner Mongolia}

Figure 2a shows the trends of average NDVI in the growing-season of Inner Mongolia during the period of 1982-2013. During the 32 years, the annual NDVI value increased slowly at a rate of 0.0003 /a and ranged from 0.3221 (in 2001) to 0.3520 (in 2012), with an average of 0.3330 . Figure 2a shows that NDVI had three distinct phases, namely a sustainable growth phase in 1982-1999, the worst vegetation growth period in 2000-2008, and rapidly increasing stages after 2008 . Possible causes of this phenomenon include low precipitation and high temperatures during the period from 2000 to 2013 in Inner Mongolia (Figs. 2b and c). In particular, higher temperatures accelerate evapotranspiration, leading to an increase in drought and a decrease in vegetation vigor (Piao et al., 2003). The rapid growth of vegetation after 2008 may be related to ecological restoration projects in addition to climatic factors (Wang et al., 2012). The average NDVI values were 0.3275 in the $1980 \mathrm{~s}, 0.3323$ in the $1990 \mathrm{~s}$, and 0.3384 in the early $21^{\text {st }}$ century, respectively, thus the best periods for vegetation growth in Inner Mongolia appeared in the 1990s. Figure 3 (i.e., growing-season NDVI) shows that NDVI values exhibited a banded structure, decreasing from northeast to southwest. NDVI of forest vegetation was the largest, and that of the desert region the smallest. The maximum NDVI value in the early $21^{\text {st }}$ century tended to spread further westward than in the previous two decades.
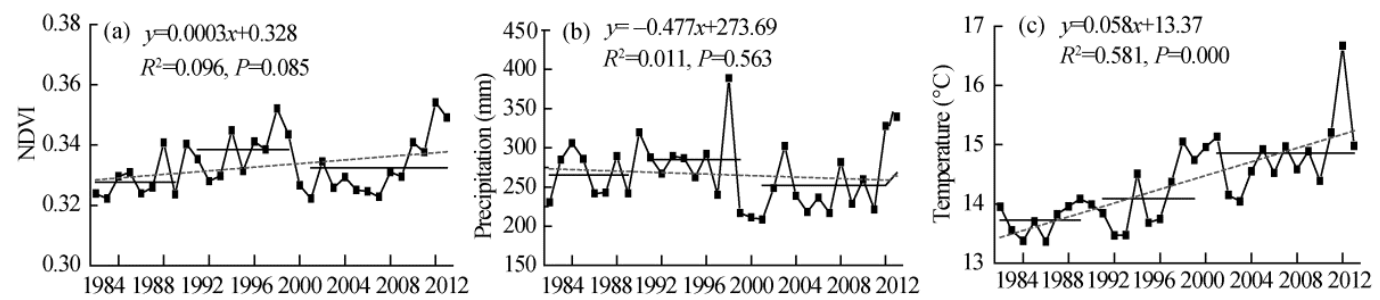

Fig. 2 Temporal trends of (a) growing-season mean NDVI, (b) precipitation, and (c) temperature in Inner Mongolia from 1982 to 2013

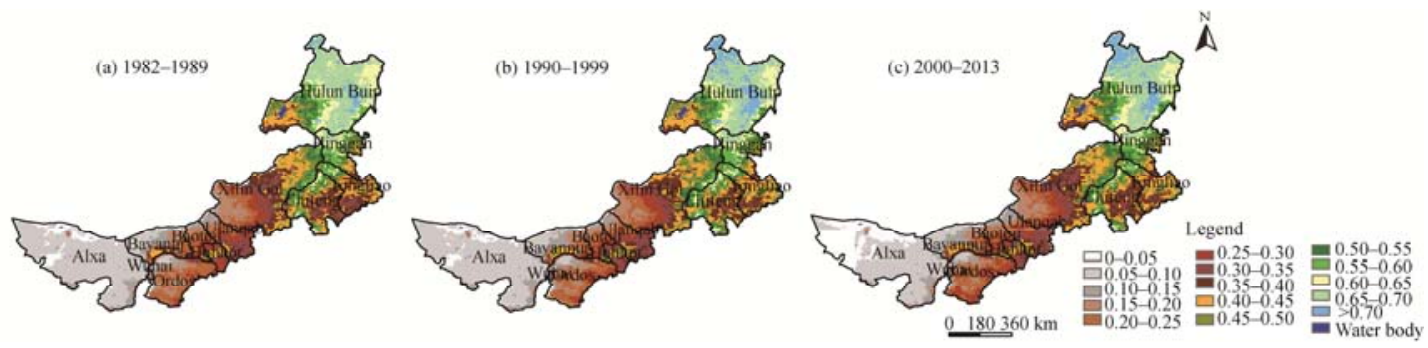

Fig. 3 Spatial distribution of vegetation cover in Inner Mongolia during three distinct periods 


\subsubsection{Spatial variations of vegetation cover in Inner Mongolia}

In order to intuitively analyze the phases of vegetation change in Inner Mongolia, we divided the spatial variations of vegetation cover into four descriptive stages: the 1980s (1982-1989), the 1990s (1990-1999), the early $21^{\text {st }}$ century (2000-2013), and the entire study period (1982-2013). Figures 4 and 5 illustrate the spatial variations of vegetation cover by correlation analysis and MK significance tests (period-by-pixel).

Spatial trends in average growing-season NDVI in the 1980s in Inner Mongolia are shown in Figure $4 \mathrm{a}: 55.4 \%$ of NDVI values (i.e., $55.4 \%$ pixels) in the region are rising, while $44.9 \%$ are declining. Specifically, NDVI values decreased in Alxa League, Bayannur City, north of Baotou City, Ulanqab City, Xilin Gol League, Sonid Left Banner, Sonid Right Banner, Taibus Banner, south of Duolun County, Ongniud Banner, Hexigten Banner in Chifeng City, and New Barag Left Banner, the Evenki Autonomous Banner, the Morin Dawa Daur Autonomous Banner, and Arun Banner in Hulun Buir City. NDVI values had rising trends in the remaining regions. Generally speaking, the change of vegetation cover in 1980s displayed an increasing trend in eastern Inner Mongolia and the change exhibited a decreasing trend in western Inner Mongolia, although neither of these trends were significant (Fig. 5a).
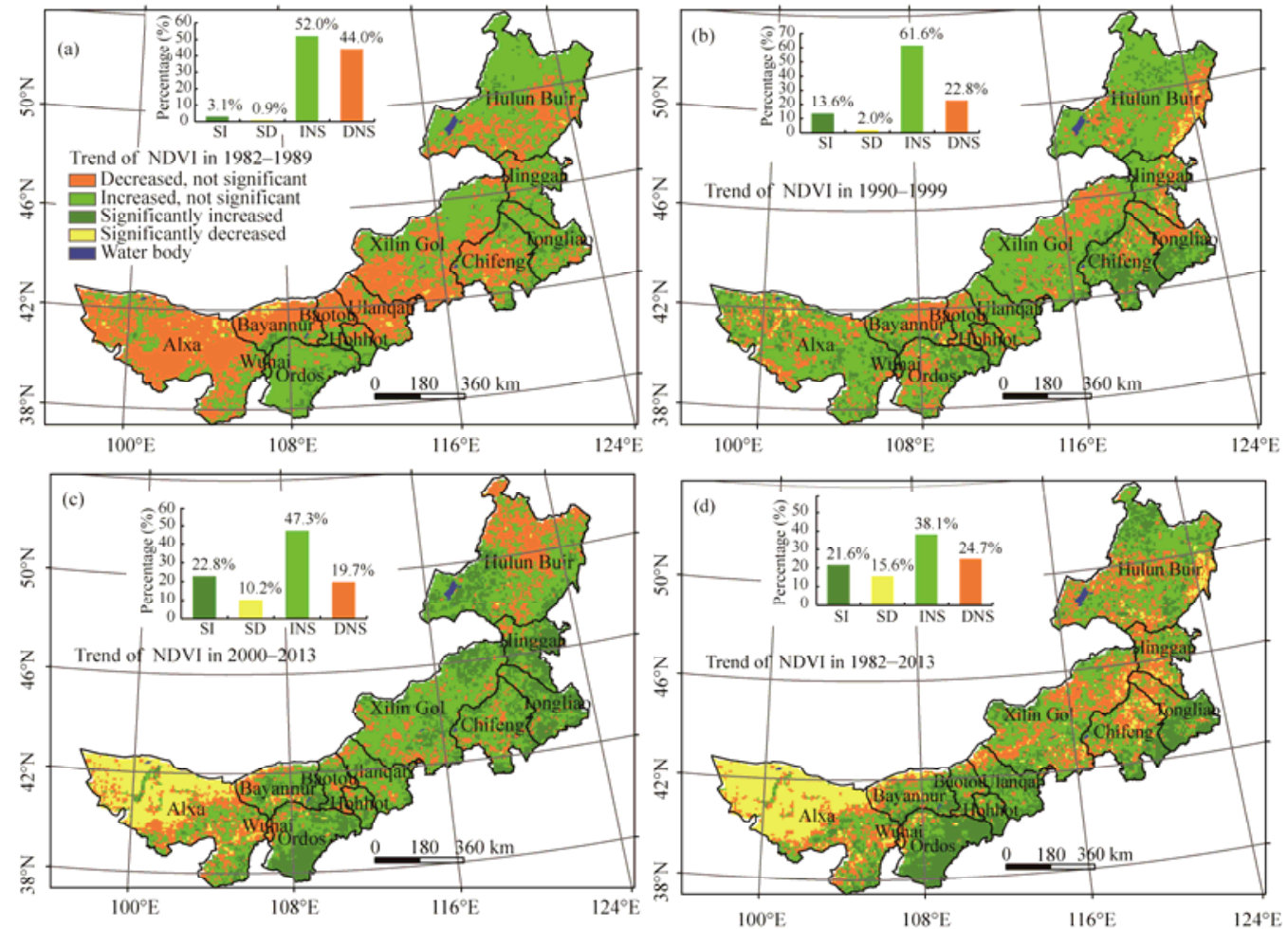

Fig. 4 Spatial patterns of changes in NDVI in Inner Mongolia during the periods of (a) 1982-1989, (b) 19901999, (c) 2000-2013, and (d) 1982-2013. SI, significantly increased; SD, significantly decreased; INS: increased, not significant; DNS: decreased, not significant.

The changing trend in average growing-season NDVI in Inner Mongolia in the 1990s shows that the area where NDVI increasing $(75.2 \%)$ was still larger than that where NDVI was decreasing (24.8\%). A significant increase in NDVI was recorded in $13.6 \%$ of the area (compared to $10.5 \%$ in the $1980 \mathrm{~s}$ ), while only $2.0 \%$ of the area, in the Morin Dawa Daur Autonomous Banner in Hulun Buir City, had a significant decreasing trend. The administrative districts where NDVI significantly increased were Chifeng City, and Naiman Banner and Hure Banner in Tongliao. The total area with decreasing NDVI declined by $11.2 \%$ compared with that in the 1980s (Fig. 4b). Overall, NDVI values in the eastern, central, and western regions of Inner Mongolia increased (though not significantly) during the period of 1990-1999 (Fig. 5b). 
Compared with the 1980s and 1990s, the area where average growing-season NDVI increased significantly (22.8\%) in the period between 2000 and 2013 (Fig. 4c) was mainly in the East Ujimqin Banner in the Xilin Gol Grassland, and Ordos City, Tongliao, Hinggan League, and other farming-pastoral zones. This shows that the forest and grassland ecological protection policies and environmental improvement projects resulted in remarkable achievements. Areas where NDVI significantly decreased in 2000-2013 grew to $10.2 \%$ compared to that in the $1980 \mathrm{~s}$ and 1990s and were mainly distributed in the western part of Inner Mongolia (e.g., Ejin Banner in Alxa League) mainly due to the elevated degree of desertification in this area in the $21^{\text {st }}$ century (Ma et al., 2015). Pixels where the NDVI did not change significantly accounted for $19.7 \%$ of the total area and were located in Ergun City, Genhe City, and Yakeshi City in Hulun Buir City. In general, NDVI values in these three regions increased, though not with statistical significance (Fig. 5c).
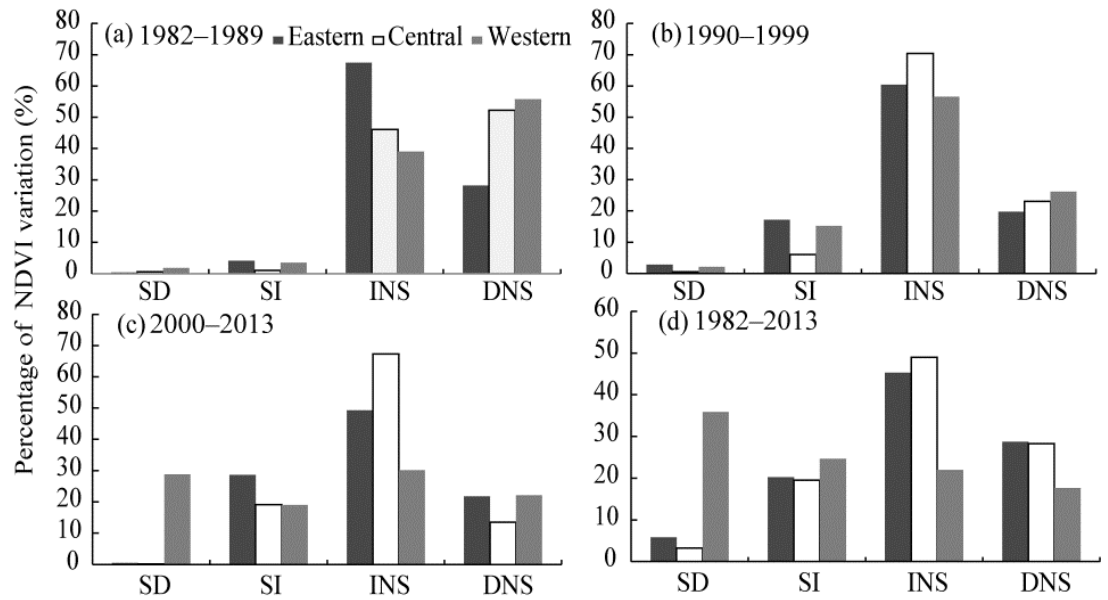

Fig. 5 Percentage of NDVI variations in three regions of Inner Mongolia during the periods of (a) 1982-1989, (b) 1990-1999, (c) 2000-2013, and (d) 1982-2013. SD, significantly decreased; SI, significantly increased; INS, increased, not significant; DNS, decreased, not significant.

The area where the growing-season NDVI in Inner Mongolia showed an increasing trend accounted for $59.7 \%$ of the total area and $21.6 \%$ had a significant increase $(P<0.05)$. The remaining area (i.e., $40.3 \%$ ) showed a decreasing trend and $15.6 \%$ had a significant reduction in the last 32 years (Fig. 4d). Areas with significant increases in vegetation cover in Inner Mongolia were mainly distributed in the Ordos grazing reforestation and ecological service area, where the ecological restoration project was a key factor in vegetation restoration (Tian et al., 2015). Aohan Banner in Chifeng City around Horqin Sandy Land, the southern part of Tongliao City, and Ergun City and Genhe City in Hulun Buir City also had significant increases in NDVI. The areas with significant reductions in NDVI were distributed in Ejin Banner and Alxa Right Banner in Alxa League, at the southern part of Hulun Buir City and Bayannur City, the Morin Dawa Daur Autonomous Banner in Hulun Buir City, and the eastern part of Xilin Gol League. The changes are the results of several factors operating individually or collectively. For example, a severe desertification occurred in 2000s in the Badain Jaran, Ulan Buh, and Tengger deserts in Alxa League (Zhang et al., 2009); mining activities were intensified in Xilin Gol League at the beginning of the $21^{\text {st }}$ century (Yang et al., 2015).

Overall, over the past 32 years the area of increasing vegetation cover in Inner Mongolia was larger than that of decreasing vegetation cover. Areas with a significant increase were mainly distributed in the southern pastoral transitional zone and Horqin Sandy areas. Figure 5 shows that during the three study periods, the NDVI values of the eastern, central, and western region mainly had a non-significant increasing trend and the trend was steeper in the 1980s and 1990s than in the early $21^{\text {st }}$ century. In the early $21^{\text {st }}$ century, the western region had a significant decreasing trend in NDVI, indicating that vegetation in western Inner Mongolia had recently experienced deterioration. 


\subsection{Relationships of vegetation changes with the changes in precipitation and temperature}

From 1982 to 2013, precipitation decreased during the growing-season in most parts of Inner Mongolia, while temperature increased (Figs. 6 and 7). Specifically, the precipitation decreased across $52.6 \%$ of the region (Hulun Buir, Hinggan League, Tongliao, Chifeng, and the eastern part of Xilin Gol League, i.e., mainly in eastern Inner Mongolia), with an average rate of reduction of $0.48 \mathrm{~mm} / \mathrm{a}$. An increasing temperature trend was found across $94.9 \%$ of the region, with a rate of increase of $0.06^{\circ} \mathrm{C} / \mathrm{a}$. In the central and western parts of Inner Mongolia, temperature and precipitation both showed increasing trends. During the growing-season the coefficient between the average NDVI and precipitation and the coefficient between NDVI and temperature showed significantly positive correlations ( $r=0.617, P=0.000 ; r=0.425, P=0.015$, respectively). The area where NDVI was positively correlated with precipitation accounted for $71.90 \%$ of the total area. It should be noted that $47.60 \%$ of the total area exhibited significantly positive correlation between NDVI and precipitation and the area included the Alxa Left Banner, Bayannur, Ordos, Hohhot, Baotou, Ulanqab, Xilin Gol League and Chifeng, Tongliao, the northern part of Hinggan League, and New Barag Right and Left Banners. The total areas of positive and negative correlations between NDVI and temperature were approximately equal, occupying $54 \%$ and $46 \%$, respectively, of the total area. NDVI in the eastern region of Inner Mongolia was negatively correlated with temperature. The central and western parts of Inner Mongolia showed positive correlations between NDVI and temperature (Fig. 8). Overall, the precipitation was the main factor affecting the growth of vegetation in Inner Mongolia (Fig. 9).

Figure 10 shows the spatial distribution of difference between the squares of two correlation coefficients (i.e., between NDVI and temperature and between NDVI and precipitation. Positive difference (i.e., difference between the squares of two correlation coefficients) indicates that the correlation of NDVI with temperature is greater than that with precipitation (the greater the value, the stronger the dominance of temperature). On the contrary, when negative difference indicates
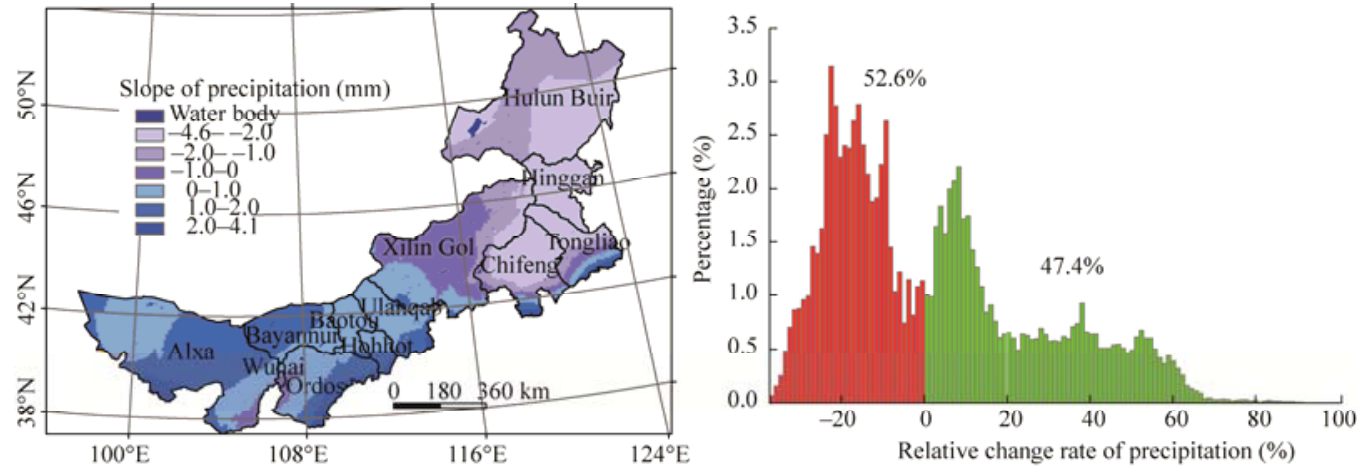

Fig. 6 Slope of annual precipitation from 1982 to 2013 calculated by linear regression and relative rate of change in annual precipitation from 1982 to 2013 (red and green indicate decreases and increases, respectively)
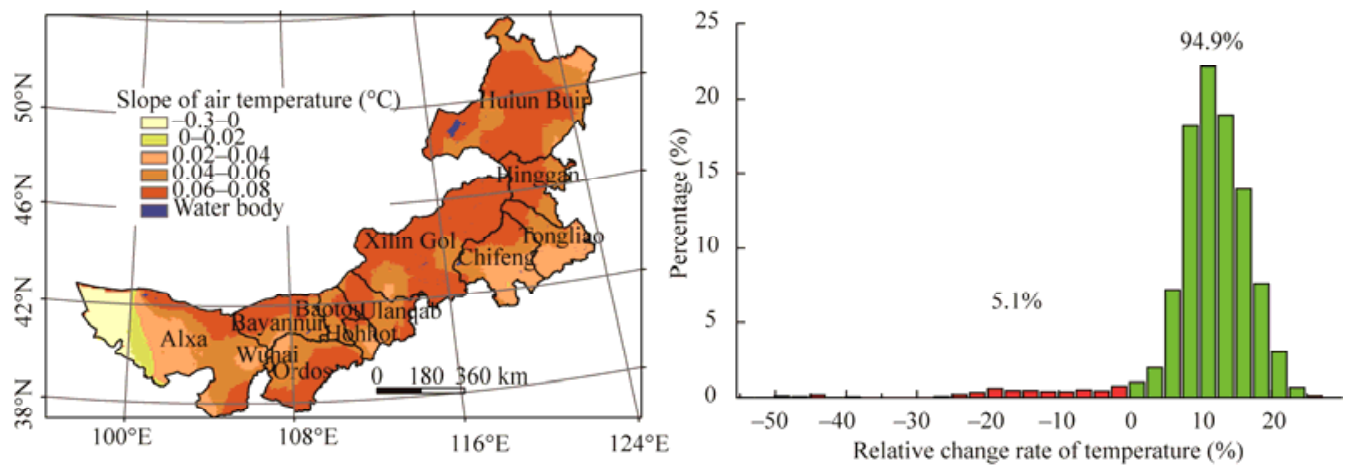

Fig. 7 Slope of annual mean air temperature from 1982 to 2013 calculated by linear regression and relative rate of change in annual mean air temperature from 1982 to 2013 (red and green indicate decreases and increases, respectively) 

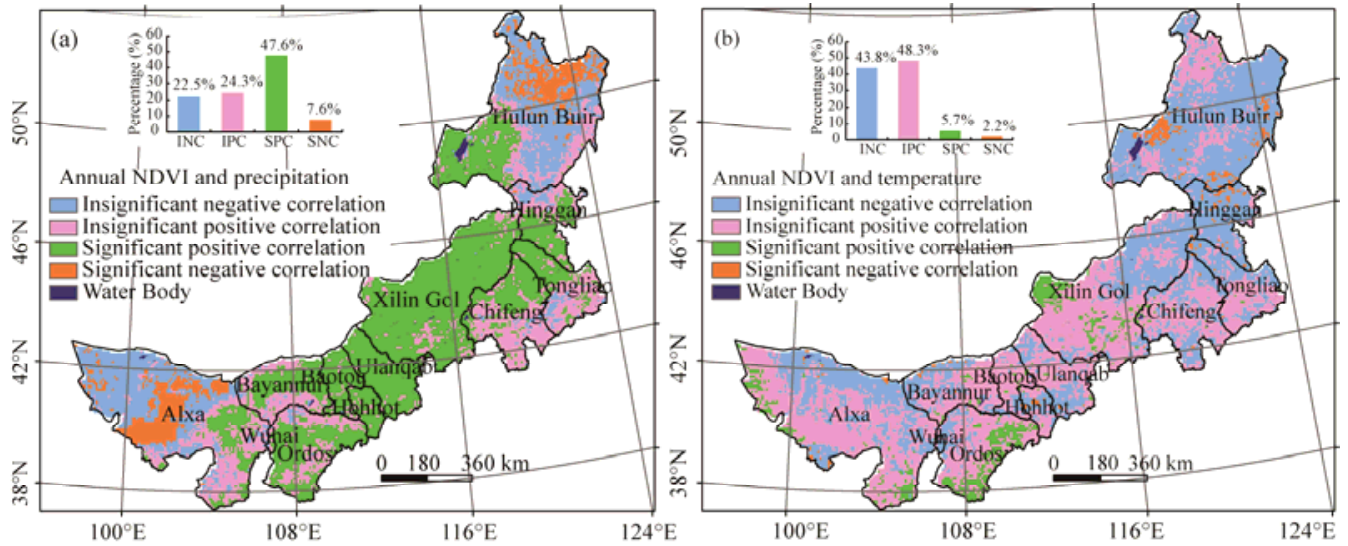

Fig. 8 Correlation between NDVI and precipitation (a) and temperature (b) in Inner Mongolia from 1982 to 2013. INC, insignificant negative correlation; IPC, insignificant positive correlation; SPC, significant positive correlation; SNC, significant negative correlation.

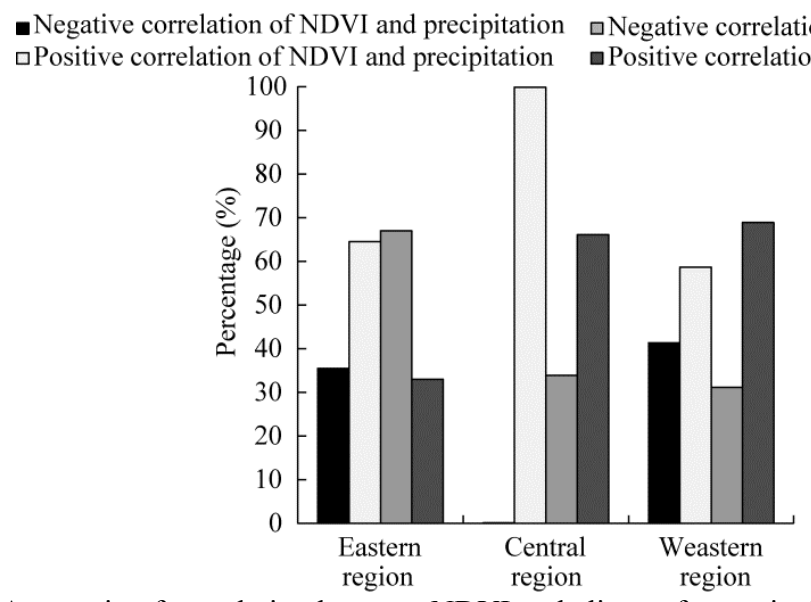

Fig. 9 Area ratio of correlation between NDVI and climate factors in different regions of Inner Mongolia

that the correlation of NDVI with precipitation was larger than that with temperature (the greater the absolute value, the stronger the dominance of precipitation). Figure 10 shows that the area where NDVI is controlled by temperature accounted for $19.3 \%$ of the total area, mainly in the northern part of the Great Hinggan Mountain foothill area of farmland, and Arun, Zalantun, the southern fringe of Alxa League, eastern regions of Bayannur City, and the northern part of Ordos. The area where NDVI is mainly controlled by precipitation accounted for $80.7 \%$ of the total area.

\subsection{Interannual variability of vegetation cover and response to climate factors}

NDVI in growing seasons had an obvious increasing trend in the entire Inner Mongolia, but regional differences were rather observable. Figure 11 illustrates the changes in growing-season NDVI, precipitation, and temperature during the period of 1982-2013 for eastern, central, and western regions. The mean growing-season NDVI did not change significantly. There was a moderate, though not significant, NDVI increase in eastern, central, and western regions $(r=0.071$, $P=0.141 ; r=0.040, P=0.273 ; r=0.108, P=0.067$; respectively), and the rate of NDVI increase in the central region $(0.0004 / \mathrm{a})$ was higher than in other regions. The mean growing-season precipitation during the period of 1982-2013 in eastern and central regions decreased slightly, while precipitation in the western region increased slightly. Mean growing-season temperatures during the period of 1982-2013 increased significantly for all three regions. The slight decreasing precipitation trend and the significant increasing temperature trend are consistent with the findings of Bao et al. $(2010,2011)$. 


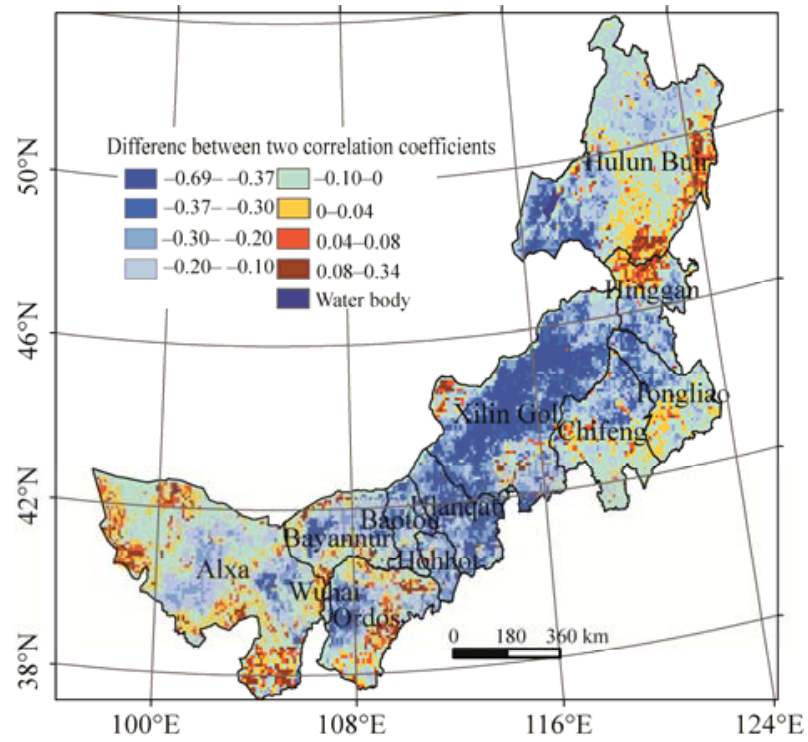

Fig. 10 Spatial distribution of difference between the square of two correlation coefficients

Figure 11 shows that NDVI fluctuations corresponded generally with precipitation fluctuations, but temperature also played a certain role most likely through modulating effective soil moisture. The correlations between NDVI and precipitation and between NDVI and temperature in the three regions during 32 years are shown in Table 1 . In the central region, growing-season precipitation was relatively high in 1998 and 2012 and low in 1989 and 2001, and the highs and lows were coinciding with peaks and troughs of growing-season NDVI (Fig. 11a). In the western region, growing-season maximum and minimum precipitations appeared in 2012 and 2005, respectively, being well correspondent with the maximum and minimum NDVIs, respectively (Fig. 11b). In the eastern region, the NDVI plateau spanning from 1986 to 2000 was approximately corresponding with the precipitation plateau spanning from 1984 to 1998. The NDVI valley spanning from 2000 to 2008 seemed to be related with the significantly lowered precipitation spanning from 1998 to 2010 and also with the elevated temperature spanning from 2000 to 2012 (Fig. 11c).

As aforementioned, the correlations of NDVI with precipitation in the central and western regions $(r=0.807, P=0.000)$ were considerably higher than that with temperature $(r=0.454$,
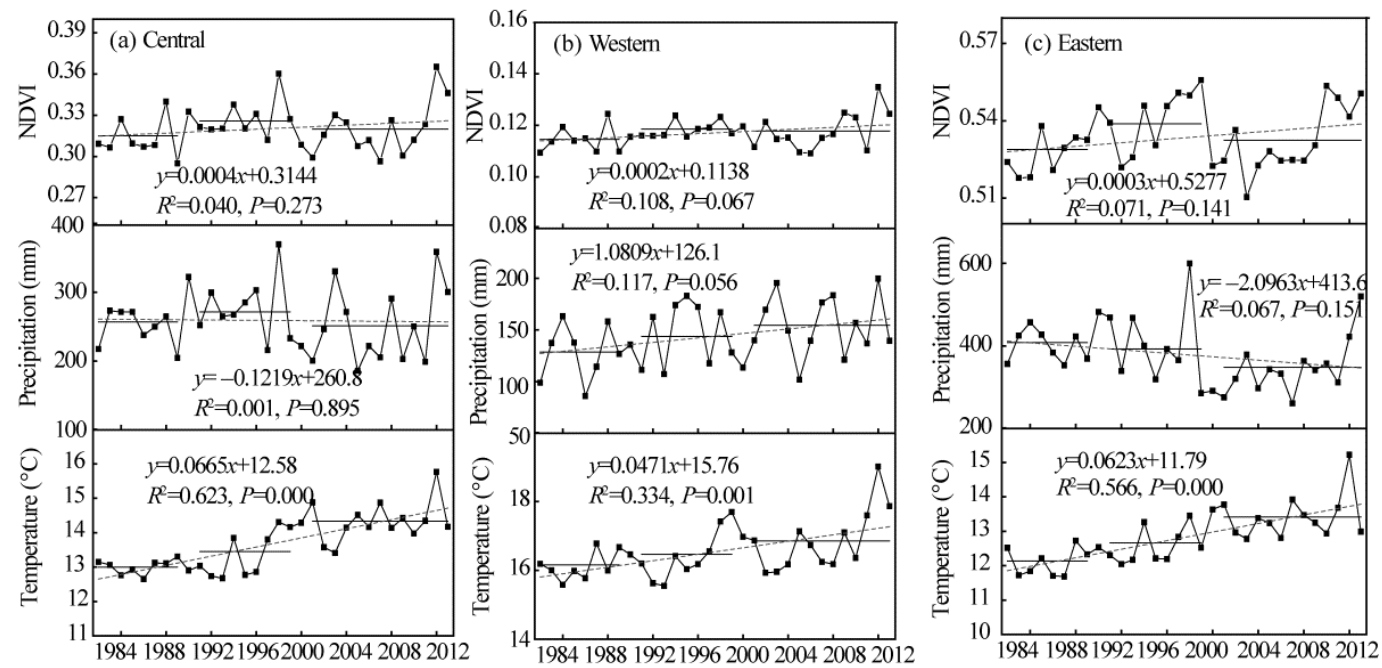

Fig. 11 NDVI variations of different regions in Inner Mongolia 
$P=0.009)$. This is because the central and western regions are climatically dry and precipitation is the limiting factor for plant growth (Li et al., 2009; Xu et al., 2010). The correlation coefficient between NDVI and precipitation was higher than that between NDVI and temperature in the eastern region, but neither was significant. For the entire Inner Mongolia, growing-season NDVI had a strongly positive correlation with precipitation $(r=0.617, P=0.000)$ and a moderately positive correlation with temperature $(r=0.425, P=0.015)$, meaning that the vegetation of Inner Mongolia grew well under the combined effect of precipitation and temperature (Zhou et al., 2001).

Table 1 Correlation coefficients between NDVI and precipitation and temperature for different districts in Inner Mongolia during the past 32 years

\begin{tabular}{lcccc}
\hline \multirow{2}{*}{ Area } & \multicolumn{2}{c}{ NDVI and precipitation } & \multicolumn{2}{c}{ NDVI and temperature } \\
\cline { 2 - 5 } & $r$ & $P$ & 0.204 & $P$ \\
\hline Eastern region & 0.269 & 0.136 & 0.158 & 0.263 \\
Central region & 0.807 & $0.000^{* *}$ & 0.259 & 0.387 \\
Western region & 0.454 & $0.009^{* *}$ & 0.425 & 0.124 \\
Whole region & 0.617 & $0.000^{* *}$ & $0.015^{*}$ \\
\hline
\end{tabular}

Note: ${ }^{*}$ and ${ }^{* *}$ indicate statistical significance at $P<0.05$ and $P<0.01$ levels, respectively.

\subsection{Interannual variability of vegetation cover and its response to climate in different vegetation zones}

Figure 12 highlights the changes in growing-season NDVI, precipitation, and temperature for coniferous forest, deciduous broadleaf forest, shrubs, grasslands, deserts, sparse forest, and croplands in Inner Mongolia from 1982 to 2013. In the 32 years, the average growing-season NDVI values of croplands showed a significant increasing trend $(r=0.243, P=0.004)$ and the average growing-season NDVI values of deserts showed a significant decreasing trend $(r=0.124$, $P=0.048$ ). Other vegetation types had increasing NDVI trends, but not significantly.
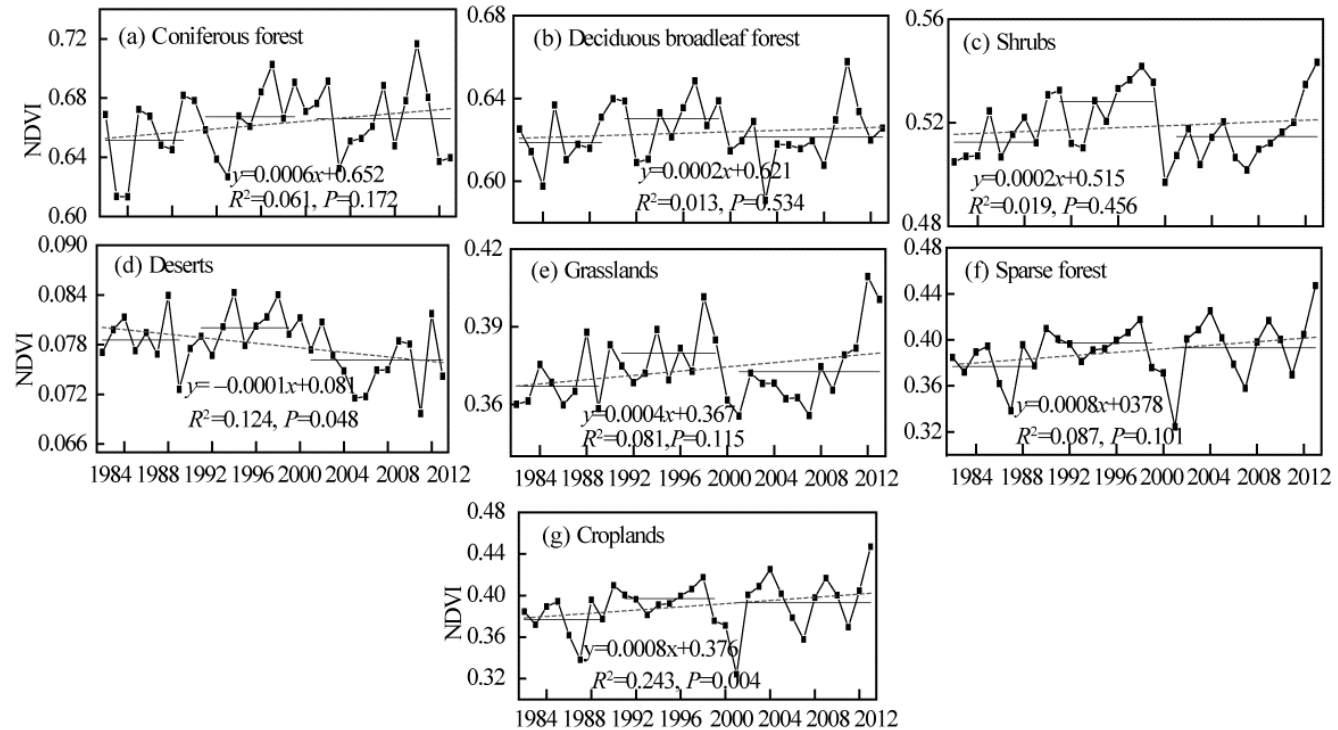

Fig. 12 Annual changes in growing-season NDVI for seven different vegetation types from 1982 to 2013 in Inner Mongolia

To examine the effects of precipitation and temperature on NDVI in different vegetation zones (types), we conducted correlation analysis for each one of the vegetation types. For shrubs, grasslands, croplands, and sparse forest, the growing-season NDVI values were significantly and positively correlated with precipitation $(r=0.507, P=0.003 ; r=0.705, P=0.000 ; r=0.581, P=0.000$; 
and $r=0.521, P=0.002$, respectively). For deciduous broadleaf forests and deserts, the growing-season NDVI values were positively correlated with precipitation, but not significantly $(r=0.016, P=0.931 ; r=0.142, P=0.439$, respectively). For coniferous forests, the growing-season NDVI values were significantly and negatively correlated with precipitation $(r=0.366, P=0.039)$. Generally speaking, the coniferous and broadleaf forests, located in northeastern Inner Mongolia, had relatively high precipitation and low temperatures, thus being conducive to vegetation growth (Shi et al., 2011). Again, the correlation between NDVI and temperature in all zones (types) of vegetation was weaker than that between NDVI and precipitation (see Table 2). Two notes deserve mentioning here. First, a negative correlation between the growing-season NDVI and temperature was observed in the deserts and this phenomenon was also reported by $\mathrm{Ma}$ et al. (2015). Second, the growing-season NDVI in the croplands was correlated neither with precipitation nor with temperature. Again, the vegetation of Inner Mongolia grew well under the combined effect of precipitation and temperature (Zhou et al., 2001).

Table 2 Correlation coefficients between NDVI and different vegetation types in Inner Mongolia during the past 32 years

\begin{tabular}{|c|c|c|c|c|}
\hline \multirow{2}{*}{ Vegetation type } & \multicolumn{2}{|c|}{ NDVI and precipitation } & \multicolumn{2}{|c|}{ NDVI and temperature } \\
\hline & $r$ & $P$ & $r$ & $P$ \\
\hline Coniferous forest & -0.366 & $0.039^{*}$ & 0.229 & 0.208 \\
\hline Deciduous broadleaf forest & 0.016 & 0.931 & 0.088 & 0.633 \\
\hline Shrubs & 0.507 & $0.003^{* *}$ & 0.127 & 0.489 \\
\hline Grasslands & 0.705 & $0.000^{* *}$ & 0.284 & 0.115 \\
\hline Deserts & 0.142 & 0.439 & -0.087 & 0.636 \\
\hline Cultivation & 0.581 & $0.000^{* *}$ & 0.001 & 0.997 \\
\hline Sparse forests & 0.521 & $0.002^{* *}$ & 0.482 & $0.015^{*}$ \\
\hline
\end{tabular}

Note: ${ }^{*}$ and ${ }^{* *}$ indicate statistical significance at $P<0.05$ and $P<0.01$ levels, respectively.

\section{Discussion}

As aforementioned, for the entire Inner Mongolia, growing-season NDVI had a strongly positive correlation with precipitation and a moderately positive correlation with temperature. Overall, the vegetation of Inner Mongolia grew well under the combined effect of precipitation and temperature. Nonetheless, a significant portion of the increase in vegetation cover was closely related to the implementation of a scheme returning farmland to forest and grassland in Beijing and Tianjin sandstorm source-control zone and the scheme included three grassland animal husbandry projects (grazing, rotational grazing ecological protection, and vegetation restoration project) and several nature reserve projects (Sun et al., 2010).

Particularly, since 2000, the Grain for Green Project in Inner Mongolia has involved 12 leagues and cities, 96 counties, and 742 towns and county subdivisions, involving $5.95 \times 10^{6}$ people in the whole autonomous region. By the end of 2004 , a total of $199.2 \times 10^{3} \mathrm{hm}^{2}$ of farmland was converted to forests or grasslands (Bao et al., 2009). Our analysis shows that the $21^{\text {st }}$ century had the highest temperature and lowest precipitation of all three decades studied and such climatic conditions are normally not conducive to vegetation growth. However, the vegetation growth during the period of 2000-2013 was relatively good, indicating that the national policy of restoration projects brought about some improvements to vegetation cover.

Admittedly, the government-intended improvements in vegetation cover have not been fully accomplished because the over-grazing and over-cultivateing issues have not been completely resolved and also because the industrialization and urbanization have recently been rapidly expanding (Huang et al., 2009). To sum up, in order to better understand the changes in vegetation cover during different periods, more in-depth investigations into climatic factors and human activities should be planned. 


\section{Conclusions}

The main conclusions of the study are summarized as follows. First, in the 32 years from 1982 to 2013, the mean growing-season NDVI in Inner Mongolia increased at a rate of 0.0003/a and the 1990s was the best period for vegetation growth. Second, the mean growing-season NDVI of three geographical regions (western, central, and eastern) had different rates of increase over the 32 years. The NDVI of the eastern and central regions increased (though not significantly), while the NDVI in the western region decreased significantly. Third, for the entire Inner Mongolia, growing-season NDVI had a strongly positive correlation with precipitation and a moderately positive correlation with temperature. Overall, the vegetation grew well under the combined effect of precipitation and temperature. Fourth, during the growing seasons of 1982-2013, average NDVI increased moderately or slightly for coniferous forest, deciduous broadleaf forest, shrubs, grasslands, sparse forest, and croplands, but decreased significantly for deserts.

One of the main challenges faced in this study was the lack of information on current economic and human activities in Inner Mongolia and thus this study was not able to quantitatively tackle the issues related to human activities. It should also admitted that this study was also not able to quantitatively assess the effectiveness of those mentioned ecological restoration projects again due to the lack of relevant data. All in all, further studies are needed.

\section{Acknowledgements}

This study was supported by the National Key Technology R\&D Program of China (2013BAK05B01, 2013BAK05B02).

\section{References}

Bao G, Qin Z H, Bao Y H, et al. 2013. Spatial-temporal changes of vegetation cover in Mongolian plateau during $1982-2006$. Journal of Desert Research, 33 (3): 918-927. (in Chinese)

Bao Y, Li X B, Li C, et al. 2010. Spatial-temporal distribution characteristics of temperature in Inner Mongolia during 19612007. Journal of Arid Land Resources and Environment, 24(12): 80-84. (in Chinese)

Bao Y, Li X B, Huang L M, et al. 2011. Spatial-temporal distribution characteristics of precipitation in Inner Mongolia from 1961-2007. Arid Land Geography, 34(1): 52-61. (in Chinese)

Chen L, Wei W, Fu B, et al. 2007. Soil and water conservation on the Loess Plateau in China: review and perspective. Progress in Physical Geography, 31(4): 389-403.

Chen X Q, Zheng T. 2008. Spatial patterns of aboveground biomass and its climatic attributions in typical steppe of Inner Mongolia. Scientia Geographica Sinica, 28(3): 369-374. (in Chinese)

Chen X Q, Wang H. 2009. Spatial and temporal variations of vegetation belts and vegetation cover degrees in Inner Mongolia from 1982 to 2003. Acta Geographica Sinica, 64(1): 84-94. (in Chinese)

Clerici N, Weissteiner C J, Gerard F. 2012. Exploring the use of MODIS NDVI-based phenology indicators for classifying forest general habitat categories. Remote Sensing, 4(12): 1781-1803.

Dong Y S, Zhang S, Qi Y C, et al. 2000. Fluxes of $\mathrm{CO}_{2}, \mathrm{~N}_{2} \mathrm{O}$ and $\mathrm{CH}_{4}$ from a typical temperate grassland in Inner Mongolia and its daily variation. Chinese Science Bulletin, 45(7): 1590-1594.

Douglas E M, Vogel R M, Kroll C N. 2000. Trends in floods and low flows in the United States: impact of spatial correlation. Journal of Hydrology, 240(1-2): 90-105.

Franklin S E, He Y H, Pape A, et al. 2011. Landsat-comparable land cover maps using ASTER and SPOT images: a case study for large-area mapping programmes. International Journal of Remote Sensing, 32(8): 2185-2205.

Guo Z X, Wang Z M, Song K S, et al. 2007. Correlations between forest vegetation NDVI and water/thermal condition in Northeast China forest regions in 1982-2003. Chinese Journal of Ecology, 26(12): 1930-1936. (in Chinese)

Holben B N. 1986. Characteristics of maximum-value composite images from temporal AVHRR data. International Journal of Remote Sensing, 7(11): 1417-1434.

Huang Y Z, Wang N A, He T H, et al. 2009. Process of historical desertification of Mu Us Desert and relationship between nature and human beings. Scientia Geographica Sinica, 29(2): 206-211. (in Chinese)

Jiang N, Zhu W Q, Zheng Z T, et al. 2013. A comparative analysis between GIMSS NDVIg and NDVI3g for monitoring vegetation activity change in the Northern Hemisphere during 1982-2008. Remote Sensing, 5(8): 4031-4044.

Li X H, Shi Q D, Guo J, et al. 2009. The response of NDVI to climate variability in northwest arid area of China from 1981 to 
2001. Journal of Arid Land Resources and Environment, 23(2): 12-16. (in Chinese)

Liu J H, Gao J X. 2009. Effects of climate and land use change on the changes of NPP in the farming-pastoral ecotone of Northern China. Resources Science, 31(3): 493-500. (in Chinese)

Liu Y, Li Y, Li S C, et al. 2015. Spatial and temporal patterns of global NDVI trends: correlations with climate and human factors. Remote Sensing, 7(10): 13233-13250.

Liu Y B, Ju W M, Chen J M, et al. 2012. Spatial and temporal variations of forest LAI in China during 2000-2010. Chinese Science Bulletin, 57(22): 2846-2856.

Ma W Y, He L, Zhao C Y. 2015. Desertification dynamics in Alxa League over the period of 2000-2012. Journal of Lanzhou University (Natural Science), 51(1): 55-60, 78. (in Chinese)

Mu S J, Li J L, Chen Y Z, et al. 2012. Spatial differences of variations of vegetation coverage in Inner Mongolia during 20012010. Acta Geographica Sinica, 67(9): 1255-1268. (in Chinese)

Na Y T. 2015. Drought characteristics in Inner Mongolia based on the SPI index in the last 50 years. Journal of Arid Land Resources and Environment, 29(5): 161-166. (in Chinese)

Niu J M. 2000. Relationship between main vegetation types and climatic factors in Inner Mongolia. Chinese Journal of Applied Ecology, 11(1): 47-52. (in Chinese)

Partal T, Kahya E. 2006. Trend analysis in Turkish precipitation data. Hydrological Processes, 20(9): 2011-2026.

Piao S L, Fang J Y, Zhou L M, et al. 2003. Interannual variations of monthly and seasonal normalized difference vegetation index (NDVI) in China from 1982 to 1999. Journal of Geophysical Research Atmospheres, 108(D14): 4401.

Piao S L, Mohammat A, Fang J Y, et al. 2006. NDVI-based increase in growth of temperate grasslands and its responses to climate changes in China. Global Environmental Change, 16(4): 340-348.

Sellers P J, Meeson B W, Hall F G, et al. 1995. Remote sensing of the land surface for studies of global change: models-algorithms-experiments. Remote Sensing of Environment, 51(1): 3-26.

Shi Z J, Gao J X, Xu L H, et al. 2011. Effect of vegetation on changes of temperature and precipitation in Inner Mongolia, China. Ecology and Environmental Sciences, 20(11): 1594-1601. (in Chinese)

Sun Y L, Guo P, Yan X D, et al. 2010. Dynamics of vegetation cover and its relationship with climate change and human activities in Inner Mongolia. Journal of Natural Resources, 25(3): 407-414. (in Chinese)

Tang H, Li Z W, Zhu Z L, et al. 2015. Variability and climate change trend in vegetation phenology of recent decades in the Greater Khingan Mountain area, Northeastern China. Remote Sensing, 7(9): 11914-11932.

Tian H J, Cao C X, Chen W, et al. 2015. Response of vegetation activity dynamic to climatic change and ecological restoration programs in Inner Mongolia from 2000 to 2012. Ecological Engineering, 82: 276-289.

Tucker C J, Townshend J R G, Goff T E. 1985. African land-cover classification using satellite data. Science, 227(4685): 369375.

Tucker C J, Fung I Y, Keeling C D, et al. 1986. Relationship between atmospheric $\mathrm{CO}_{2}$ variations and a satellite-derived vegetation index. Nature, 319(6050): 195-199.

Tucker C J, Pinzon J E, Brown M E, et al. 2005. An extended AVHRR 8-km NDVI dataset compatible with MODIS and SPOT vegetation NDVI data. International Journal of Remote Sensing, 26(20): 4485-4498.

Wang J, Li B L, Yu W L. 2012. Analysis of vegetation trend and their causes during recent 30 years in Inner Mongolia Autonomous Region. Journal of Arid Land Resources and Environment, 26(2): 132-138. (in Chinese)

Wang Z S, Huang M, Yan H M, et al. 2015. Spatiotemporal variation of vegetation and climate impacts on it in Ghana from 1982 to 2006. Journal of Geo-Information Science, 17(1): 78-85.

Xin L J, Li X B, Tan M H, et al. 2015. Spatial and temporal variability in grassland Net Primary Production (NPP) in the Inner Mongolia sand-control belt from 2000 to 2010. Arid Zone Research, 32(3): 585-591. (in Chinese)

Xu X, Li X B, Liang H W, et al. 2010. Change in vegetation coverage and its relationships with climatic factors in temperate steppe, Inner Mongolia. Acta Ecologica Sinica, 30(14): 3733-3743. (in Chinese)

Xue Z C, Gao H Y, Peng T, et al. 2011. Application of spectral reflectance on research of plant eco-physiology. Plant Physiology Journal, 47(4): 313-320.

Yang Q, Wang T T, Chen H, et al. 2015. Characteristics of vegetation cover change in Xilin Gol League based on MODIS EVI data. Transactions of the Chinese Society of Agricultural Engineering, 31(22): 191-198. (in Chinese)

Zhang B P, Zhang X Q, Yao Y H, et al. 2009. Desertification and strategic policies in the Alxa region of Inner Mongolia. Arid Zone Research, 26(4): 453-459. (in Chinese)

Zhang X B, Vincent L A, Hogg W D, et al. 2000. Temperature and precipitation trends in Canada during the $20^{\text {th }}$ century. Atmosphere-Ocean, 38(3): 395-429.

Zhou L M, Tucker C J, Kaufmann R K, et al. 2001. Variations in northern vegetation activity inferred from satellite data of vegetation index during 1981 to 1999. Journal of Geophysical Research: Atmospheres, 106(D17): 20069-20083. 